\title{
Integrating MOOCs into a Technology-Enhanced Course for Undergraduate Students
}

\author{
Jarrent R. Tayag ${ }^{1, *}$, Mary Rose M. Tayag ${ }^{2}$ \\ ${ }^{1}$ College of Education, Angeles University Foundation, Philippines \\ ${ }^{2}$ College of Business and Accountancy, Angeles University Foundation, Philippines
}

Received February 25, 2020; Revised March 16, 2020; Accepted March, 28, 2020

Copyright $\bigcirc 2020$ by authors, all rights reserved. Authors agree that this article remains permanently open access under the terms of the Creative Commons Attribution License 4.0 International License

\begin{abstract}
Massive Open Online Courses (MOOCs) are gaining significant interest and support in the education sector, particularly in higher education. Universities are investing into the production and dissemination of these courses to attract students and professionals. In this study, the experiences of students in completing MOOCs are described. Eighty-two undergraduate students enrolled in a college course were asked to select and enroll in a MOOC at the beginning of the term. The students were given a maximum of three months to complete a MOOC of their choice. Most of the students were able to select an online course that lasted for eight weeks. Following a sequential explanatory mixed methods design, the researchers conducted a survey among 82 undergraduate students about their completion or non-completion of their chosen MOOCs. From the findings, representative samples were taken and interviewed to better understand what the students experienced while they are engaging into the online course. Contrary to reported figures, the students had high completion rate $(70 \%)$, but most of them completed the course a week before the end of the 3-month period. Qualitative analyses of the interview transcripts revealed that the lack of connectivity, time, and interactivity, as well as conflict with their face-to-face class activities hindered them from completing the online course. Despite these, the participants recognized the potentials of MOOCs in providing access to valid and reliable information about a diverse array of disciplines. Prospects for higher education are discussed.
\end{abstract}

Keywords Massive Open Online Courses, Higher Education, Mixed Methods Design

\section{Introduction}

Massive Open Online Courses (MOOCs) have gained impetus in the recent decade [1]. With the advent of more sophisticated platforms for creating and disseminating online courses, universities from different countries have invested into converting their courses into online versions [2]. This allowed them to have farther and wider reach. In most cases, MOOCs are used to advertise actual courses that are offered by the universities. Consortium of MOOCs such as Coursera has attracted a huge number of students and professionals. At present, MOOCs are offered for wide array of disciplines.

Khalil and Ebner, however, noted that while students may have great interest in participating in MOOCs, several factors appear to contribute to the high dropout rates among these courses [3]. They particularly cited the lack of interactivity, time, and insufficient background skills and knowledge. Online learning seems to be well suited for adult learners who may already have mastered independent learning. The unsupervised, self-paced learning offered by MOOCs could sometimes prove to be detrimental for younger learners. For professionals, the lack of time appropriated for online tasks is often identified as an issue in completing the course.

Despite these, the growing popularity of MOOCs can be attributed to the increased access of valid and reliable information. A growing number of researches is geared towards developing a streamlined paradigm for online learning to which MOOCs can thrive. Higher education, in particular, can find the opportunities offered by MOOCs to be beneficial in their goal of cultivating a culture of higher learning and providing better access to this information. The present study aimed to describe the experiences of undergraduate students in participating in MOOCs in a technology-enhanced classroom. A deeper understanding of the encounters of students as they engage into MOOCs can provide significant inputs in the streamlining of educational paradigms that could eventually support the effective integration of MOOCs in the higher education system. 


\section{Literature Review}

MOOCs have provided relatively new venue for universities to fulfill their mandate to create knowledge and ensure wide dissemination of these knowledge [4]. While emerging models of MOOCs are far from their rudimentary beginnings [26], MOOCs are undoubtedly providing alternative platforms for the delivery of instruction and training in the higher education.

MOOCs have been used to bridge skill gaps among new graduates who enter the industry without enough competencies [5]. This supports the contention that online courses are to be designed for the acquisition of skills that may or may not be developed in the regular face-to-face classrooms. For instance, while students may have the ability to acquire critical thinking through active interaction in the classroom, a big class size may hamper the opportunities for them to interact and participate. Indeed, it may be contested that pedagogical accommodations can address such situations. However, higher education classrooms are often pressed with limitations such as course schedules and demands to afford these kinds of whole class explorations. In these instances, MOOCs may provide the individualized pace for learning the necessary skills.

Unfortunately, despite the promise of MOOCs towards accessible education, a framework to guide educators and course designers is still being developed [6]. As a result, most of these online courses are but valiant attempts to mimic face-to-face classes, an effort that is likely to fail because of the substantial difference between the two. The lack of pedagogical quality of MOOCs is also a valid concern that must be taken into consideration in the formulation of relevant policies and programs for these online courses [7].

Social mobility for underprivileged students who cannot afford higher education has also been provided by MOOCs [4]. At the same time, privileged learners are likewise given the same access for such courses. Improvement in student performance has been noted by several researches [8]. This implies that MOOCs could indeed be instrumental in enhancing the dissemination of information and allowing a diverse group of learners acquire desired skills and knowledge [9] [10]. Several studies like that of Larionova and her associates [28] even noted academic gains for students who studied under the MOOC platform over those in the face-to-face sessions. Tang [29] points to the ability of MOOCs to provide mastery learning in explaining the possible academic gains among students. Huang, Zhang, and Liu [30], however, noted that the intention of students to revisit MOOCs is negatively moderated by the course difficulty. These findings open a new array of studies for the understanding of the mechanisms by which MOOCs can impact the academic performance and achievement of students in the higher education.
While there has been increasing interest towards MOOCs from researchers, Liyanagunawardena, Adams, and Williams [2], through a systematic review of literature from 2008-2012, noted the dearth of qualitative studies relating to the experiences of learners under this platform. A notable study could be that of Meneses, Cano, and Mac Fadden [22], in which they implemented a qualitative analysis of responses from students who have completed a MOOC. The study cited issues on didactics and assessment as impediments to complete the course. These challenges are apart from the persisting problems of many countries like China in infrastructures [25]. On the other hand, similar to other studies, the wide and open access $[23,24]$ and establishment of networks [24, 27] were acknowledged as benefits of implementing MOOCs.

\section{Materials and Methods}

\subsection{Research Design}

The study employed a sequential explanatory mixed methods design, in which quantitative data were gathered prior to the collection of qualitative data. This design is appropriate in providing an in-depth explanation of trends that are established through quantitative methods. For the quantitative phase, survey design is used to determine the completion rate of the students in the MOOCs that they have chosen. From these data, a sample of students who completed and did not complete the course were selected for interviews.

A technology-enhanced environment was adopted for the educational technology course. During this 4-month course, the students met regularly face-to-face. At the same time, students are given online tasks such as activities through a learning management system (LMS). At the onset of the educational technology course, the students were introduced to Coursera, a platform for MOOCs. During the first week, the students were asked to select an online course that they would like to enroll to. Some considerations set for the selection of the course are the time frame (must be completed in 2-3 months), the student's interest, and the course content (must be related to educational technology). After selecting their courses, the students enrolled for free. As soon as they have enlisted themselves to the course, the students were given the free hand as to when they are to start reading the materials and doing the activities in the course they have selected. Reports on the completion of the course were submitted at the end of the 3-month period. Alongside the students' attendance to the MOOC, they regularly attend a face-to-face session for the course. Students are allowed to use the materials that they learned from the MOOC in the face-to-face sessions. However, the students are not required to this as other materials were made available in line with the course. 


\subsection{Data Sources}

Qualitative data were gathered through interviews, observations, and online monitoring of student activities. Interviews were meticulously transcribed to identify recurring themes. These were also triangulated with observations of student activities during the face to face and online sessions. The interviews and observations were centered on the potential benefits and challenges that the students have encountered while participating in MOOCs. Implications and prospects were eventually drawn from the analyses of the data and survey of existing literature.

\subsection{Participants}

The study was participated in by 82 undergraduate students from a university. All the students are taking up education courses. They were taking up an educational technology course during the conduct of the study. The students were 19-23 years old. The entire sample comprises of 23 males $(28 \%)$ and 59 females $(72 \%)$.

\section{Results and Discussion}

The initial phase of the study involved a profiling of the students' completion rates in their chosen MOOCs. Two items were included in the survey: whether they have completed the MOOC or not, and when did they complete the MOOC.

\subsection{Completion of MOOC}

Of the 82 participants, only $57(70 \%)$ were able to complete the MOOC that they have chosen. Figure 1 shows the relative completion rate for males and females.

Relative to the percentage of students who completed the MOOC, there are more females $(42=71 \%)$ who completed their chosen courses compared to males $(15=65 \%)$. While the percentage difference may not be very significant, it is worthy to note that such completion rates can be considered higher than the reported completion rates for MOOCs [3]. A feasible justification for this is the fact that the MOOC completion serves as a course requirement for the students. However, even if this is a course requirement, it is still interesting to explore why several students persist not to complete the MOOC.

Another significant finding from the survey is the time it took for the students to complete their MOOC. It has been mentioned that prior to the selection of the MOOC, the students were reminded to consider a course that they can complete in two to three months. Most of the students chose MOOCs that lasted for eight weeks. Figure 2 shows that most of the students completed the MOOCs a week before the end of the 3-month period.

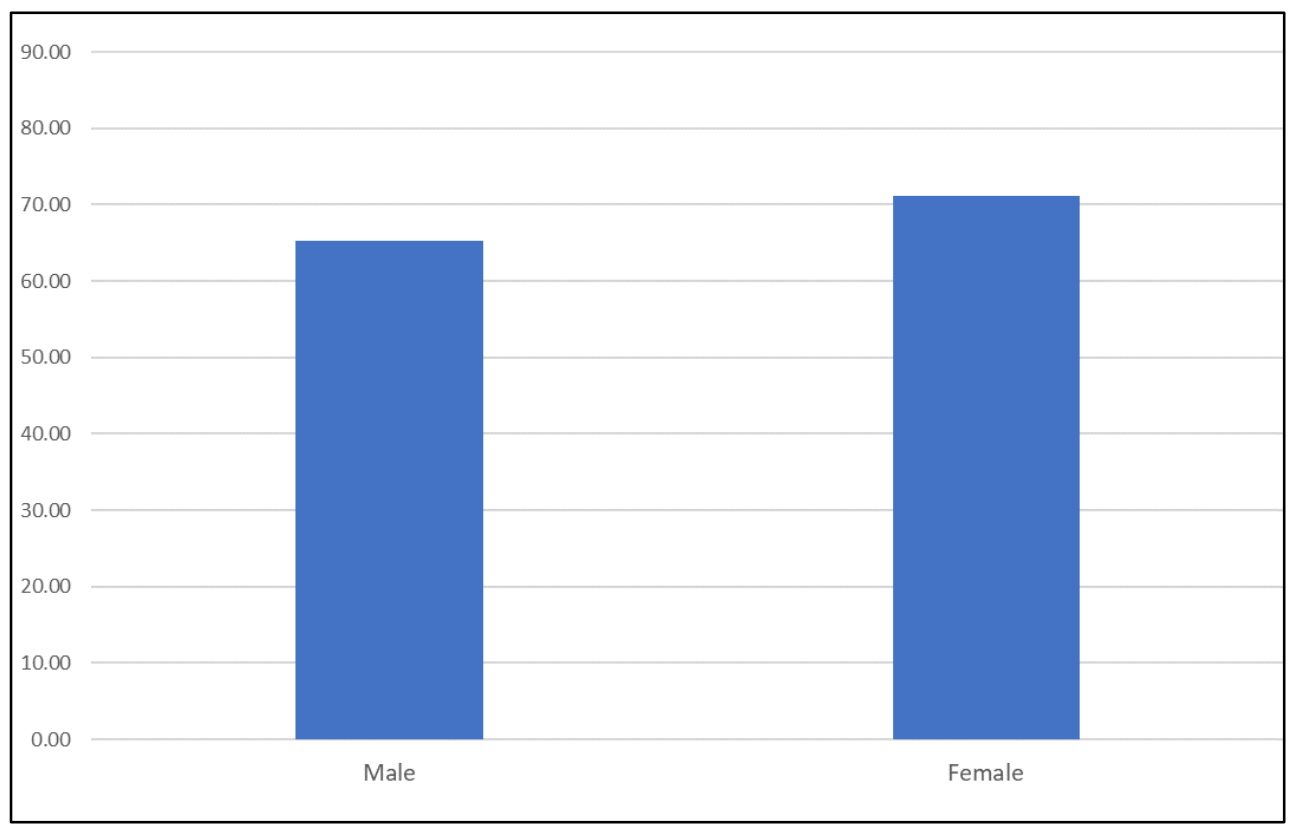

Figure 1. Percentage comparison of MOOC completion for male and female 


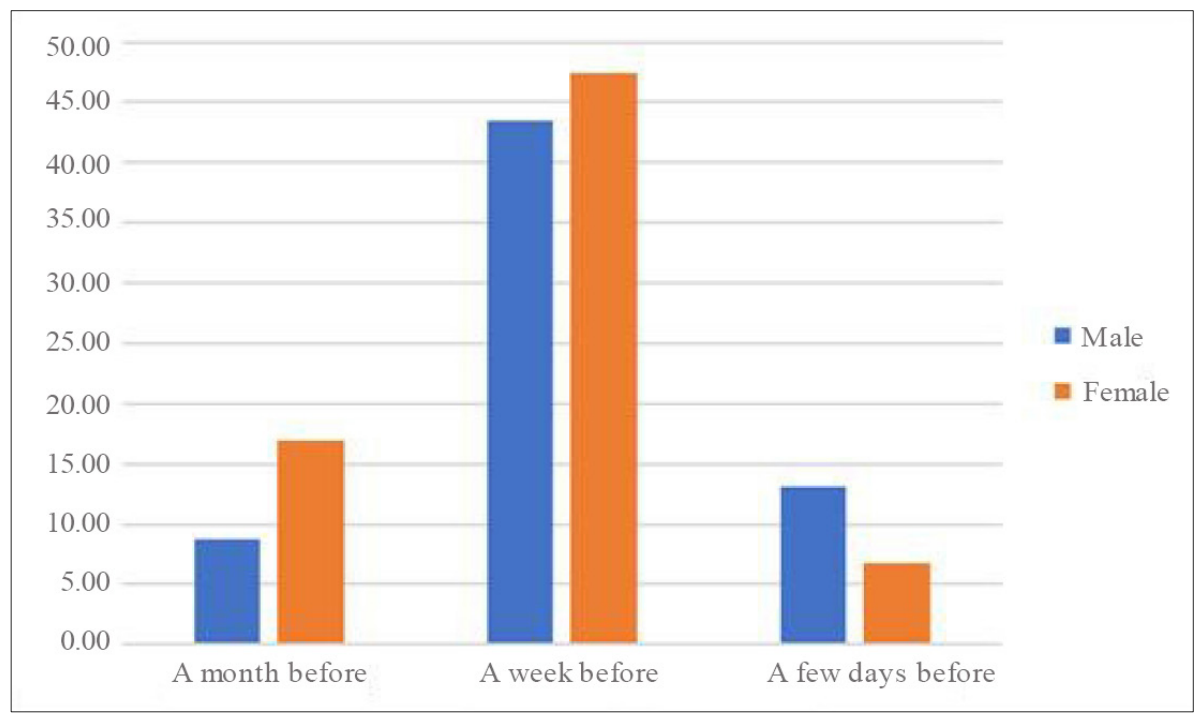

Figure 2. Percentage comparison of completion time

Interestingly, there were more females to complete the MOOC a month before compared to males. In contrast, there were more males who completed the MOOC a few days before the end of the 3-month period. These findings could enrich the investigations conducted by Morris, Swinnerton, and Hotchkiss [11], in which they related demographic variables towards the likelihood to complete MOOCs. While they failed to establish that gender can have a significant relation to the completion of students, they have noted that substantial differences were noticed in some course content. Jiang, Schenke, Eccles, $\mathrm{Xu}$, and Warschauer [12], however, noted that females have higher potential of completing science and technology-related MOOCs. Meier, Reinecke, and Meltzer [13] found that the availability of social media and other online materials can distract students from completing tasks. Taking this concept into the trend seen in Figure 2, it may be surmised that students tend to delay the completion of the course that they have chosen until the last few days. However, it would be unfair at this point to attribute such delay to their engagement to social media as various factors may intervene in the task.

\subsection{Challenges in Completing MOOCs}

From the results of the survey, eight students were selected for interview. Two of the selected students were not able to complete the MOOC. For those who completed the MOOC, six students were chosen - two from each of the categories: completed the course a month before, a week before, and a few days before. The focus of the interview is to explore in detail the perspectives of the students in the task.

\subsubsection{Inaccessibility or Lack of Connectivity}

MOOCs are solely accessible through the internet; thus, in cases where connectivity is limited, tasks related to the
MOOC cannot be completed. In most of the MOOCs taken by the students, they were required to watch short video discussions. Because of the limited access, students cannot watch these videos and thus cannot complete the tasks. While connectivity is available in the school campus, students are pre-occupied in attending classes and completing other academic tasks. Most of the students stated that the best time for them to access their MOOCs is when they are at home or in their dormitories. In school, they opt to use their time performing group tasks.

There were instances wherein the limited connectivity cause frustration among the students. One student noted that she had to retake the entire quiz simply because her internet connection lagged the moment she was about to submit her answers. Another student had almost forgotten to turn in her paper because she did not have connectivity at the time she completed it. She waited for an opportunity to upload the file but eventually forgot about it.

\subsubsection{Lack of Time}

MOOCs are designed to support students with limited time to learn concepts. In most cases, videos are kept short and staggered to several parts so that students can watch them even during their break periods. Readings are readily available and can be downloaded so students can also access them any time. However, despite these conveniences, students still find it difficult to fit into their schedule of their MOOC activity. One student even mentioned that he completed the course in a few days because he almost forgot about the tasks that he is to complete. He frequently receives email from Coursera reminding him of the deadlines, but he simply does not conscientiously include these in his daily schedule.

In some cases, it appears that the concerns on time is not caused by the lack of it, but rather, the creation of a false appreciation of the complexity of the task. One student who was not able to complete the course reasoned that he has 
checked on the tasks and thought that he would simply need a few days to complete them. This made him set aside the tasks until a few days before the deadline. Unfortunately, when he was doing the tasks, he realized that they were more difficult than they seem. Inasmuch as he wanted to complete the course on time, he was not able to do all the tasks. One of the tasks required him to do a peer-review of a paper. However, since he was doing it towards the end of the course, there were not available submissions that he could review, rendering him unable to have a mark for that particular task.

\subsubsection{Conflicts with Face-to-face Tasks}

The authors caution readers in taking the results without considering the context in which the study was founded. MOOC is integrated into the face-to-face sessions of the students. This means that the students are still required to attend the regular schedule that they have in the university. Further, only their educational technology education course required the attendance in MOOC. This implies that for all the other courses of the students, they have to complete several other requirements that they have to accomplish within strict deadlines. This context can lead to a better understanding of why the students felt that there is conflict in the different tasks that they have. While online tasks in their MOOCs also have their set deadlines, they find their other university requirements more urgent. After all, because of the individualized pacing provided in the MOOC, they understand that they can always catch up and complete their tasks just before the closing of the course.

This issue poses concerns on the availability of instructor support. Previous studies assert that while there may not be significant difference in the achievement of students in both face-to-face and online environments [14] [15] [16], student satisfaction is higher for their instructors in face-to-face classes [14]. In the light of the present study, the students may have found the lack or limited human interaction in the MOOC to be an inhibitor for them to immediately comply with the MOOC requirements. In contrast, teachers in their face-to-face classes can provide regular reminders and assistance for them to complete their course requirements.

\subsubsection{Lack of Interactivity among MOOC Participants}

Many of the students have noted that the MOOCs that they have enrolled into required them to do peer-review. In this task, they are required to submit a paper and review and assess at least two papers from others who are enrolled in the same MOOC. These tasks are also bound by deadlines, usually two weeks. Unfortunately, many of the MOOCs are not populated making it almost impossible for them to comply with the requirement. While Billington and Fronmueller [17] have projected that the number of people who are to engage into MOOCs and other online platforms are likely to increase especially in the higher education, the availability of a wide collection of MOOCs make it a challenge to populate them with enrollees. This causes a deterrent for the prospective that MOOCs can serve as micro-communities of learners, who have erased the boundaries of geography. Because of the availability of MOOCs for various disciplines, people have also been keen in choosing which course to take. Jordan [18] noted that enrolment in MOOCs have decreased, but the completion rate is gradually increasing especially for new courses. This could suggest the influence of newer and more relevant content to be more enticing for the population of learners.

Another perspective to look at the result is the probable lack of self-control in learning of some people enrolled in MOOCs [19]. Khalil and Ebner [3] reported a relatively high dropping rate among MOOC participants, causing tasks such as peer-review to be left with a handful of active participants. Some MOOCs do not have an assigned instructor who can religiously monitor the performance of the students and provide feedback. Thus, students often feel that they are alone even if the task is actually calling for learner collaboration.

\subsection{Prospect for the Use of MOOCs in Higher Education}

MOOCs are undoubtedly opening new gateways for higher education with the increased accessibility of information. Through MOOCs, the students have had access to information from other universities from around the world. With the persisting problem of false information proliferating in the internet, MOOCs can become vanguards of valid and reliable information that university students can use in understanding concepts and mastering skills. Several universities have started to consider the possibility of crediting completed MOOCs in the baccalaureate degree of the students. Others have designed degrees to be obtained through MOOCs. With these possibilities, it is essential that an appropriate paradigm be developed to ensure that students maximize the opportunities that they can get from this platform.

The model of integration reported in this study is far from ideal. The conflict between the face-to-face sessions and online activities of the students must be addressed to ensure that learning is optimized. For some universities transitioning to full online implementation of their courses may not be within their targets for the next several years. For one, there is a need to consider whether the instructors are capable of delivering online courses, like that in MOOCs [20] [21]. Second, universities must invest in the creation of their own MOOCs to properly address the contextual needs of their learners. The course involved in this study is quite generic in the sense that educational technology may have a common definition at least in most societies. However, it can still pose a challenge on what kind of materials are discussed in the MOOC and how relevant they are in the lives of the students. 
In a way, having courses delivered through MOOCs can make instructors augment the actual classes that they have to attend. When materials and tasks are automatically prompted through the MOOC platform, the instructor simply has to monitor forums or respond to queries from the enrolled learners. Further, this will also enable universities to break the limits on the number of enrollees that they can uptake in a given semester.

\section{Conclusions}

The present study aimed to describe experiences of undergraduate students in participating in MOOCs in a technology-enhanced course. The completion rate of the students for the chosen MOOC is at $70 \%$, a figure higher than most of the reported completion rates from previous studies. Despite giving the students three months to complete their chosen MOOC (average required time $=8$ weeks), students were reported to complete their MOOCs a week before the end of the 3-month period. A closer investigation to this behavior revealed that the lack of connectivity, time, and interactivity, and conflict with face-to-face tasks are among the primary reasons why students are not able to complete their MOOCs or are able to complete them late. These findings can serve as inputs for MOOC designers and higher education institutions planning to offer their courses through MOOCs.

The higher education may significantly benefit from the offering of MOOCs. These platforms can increase the reach of universities and allow them to increase their uptake of enrollees. However, instructors and administrators must take into account the limitations that surfaced in the present study.

\section{REFERENCES}

[1] Gamage, D., Fernando, S., \& Perera, I. (2015, August). Quality of MOOCs: A review of literature on effectiveness and quality aspects. In 2015 8th International Conference on Ubi-Media Computing (UMEDIA) (pp. 224-229). IEEE.

[2] Liyanagunawardena, T. R., Adams, A. A., \& Williams, S. A. (2013). MOOCs: A systematic study of the published literature 2008-2012. The International Review of Research in Open and Distributed Learning, 14(3), 202-227.

[3] Khalil, H., \& Ebner, M. (2014, June). MOOCs completion rates and possible methods to improve retention-A literature review. In EdMedia + innovate learning (pp. 1305-1313). Association for the Advancement of Computing in Education (AACE).

[4] van de Oudeweetering, K., \& Agirdag, O. (2018). MOOCS as accelerators of social mobility? A systematic review. Journal of Educational Technology \& Society, 21(1), 1-11.

[5] Santandreu Calonge, D., \& Aman Shah, M. (2016). MOOCs, graduate skills gaps, and employability: A qualitative systematic review of the literature. International Review of Research in Open and Distributed Learning: IRRODL, 17(5), 67-90.

[6] Joksimović, S., Poquet, O., Kovanović, V., Dowell, N., Mills, C., Gašević, D., ... \& Brooks, C. (2018). How do we model learning at scale? A systematic review of research on MOOCs. Review of Educational Research, 88(1), 43-86.

[7] Duart, J. M., Roig-Vila, R., Mengual-Andres, S., \& Maseda, D. (2017). The pedagogical quality of MOOCs based on a systematic review of JCR and Scopus publications (2013-2015). Revista española de pedagogía, 75(266), 29-46.

[8] Zhu, M., Sari, A., \& Lee, M. M. (2018). A systematic review of research methods and topics of the empirical MOOC literature (2014-2016). The Internet and Higher Education, 37, 31-39.

[9] Rolfe, V. (2015). A systematic review of the socio-ethical aspects of Massive Online Open Courses. European Journal of Open, Distance and E-learning, 18(1), 52-71.

[10] Wong, J., Baars, M., Davis, D., Van Der Zee, T., Houben, G. J., \& Paas, F. (2019). Supporting self-regulated learning in online learning environments and MOOCs: A systematic review. International Journal of Human-Computer Interaction, 35(4-5), 356-373.

[11] Morris, N. P., Swinnerton, B. J., \& Hotchkiss, S. (2015). Can demographic information predict MOOC learner outcomes? In Experience Track: Proceedings of the European MOOC Stakeholder. Leeds.

[12] Jiang, S., Schenke, K., Eccles, J. S., Xu, D., \& Warschauer, M. (2016). Females' enrollment and completion in science, technology, engineering, and mathematics Massive Open Online Courses. arXiv preprint arXiv:1608.05131.

[13] Meier, A., Reinecke, L., \& Meltzer, C. E. (2016). "Facebocrastination"? Predictors of using Facebook for procrastination and its effects on students' well-being. Computers in Human Behavior, 64, 65-76.

[14] Johnson, S. D., Aragon, S. R., \& Shaik, N. (2000). Comparative analysis of learner satisfaction and learning outcomes in online and face-to-face learning environments. Journal of interactive learning research, 11(1), 29-49.

[15] Dell, C. A., Low, C., \& Wilker, J. F. (2010). Comparing student achievement in online and face-to-face class formats. Journal of online learning and teaching, 6(1), $30-42$.

[16] Larson, D. K., \& Sung, C. H. (2009). Comparing student performance: Online versus blended versus face-to-face. Journal of Asynchronous Learning Networks, 13(1), 31-42.

[17] Billington, P. J., \& Fronmueller, M. P. (2013). MOOCs and the future of higher education. Journal of Higher Education Theory and Practice, 13(3/4), 36-43.

[18] Jordan, K. (2015). Massive open online course completion rates revisited: Assessment, length and attrition. International Review of Research in Open and Distributed Learning, 16(3), 341-358.

[19] Littlejohn, A., Hood, N., Milligan, C., \& Mustain, P. (2016). Learning in MOOCs: Motivations and self-regulated 
learning in MOOCs. The Internet and Higher Education, 29, 40-48.

[20] Kay, J., Reimann, P., Diebold, E., \& Kummerfeld, B. (2013). MOOCs: So many learners, so much potential... IEEE Intelligent systems, 28(3), 70-77.

[21] Blackmon, S. (2018). MOOC makers: Professors' experiences with developing and delivering MOOCs. International Review of Research in Open and Distributed Learning, 19(4).

[22] Meneses, E. L., Cano, E. V., \& Mac Fadden, I. (2020). MOOC in Higher Education from the Students' Perspective. A Sustainable Model? In Qualitative and Quantitative Models in Socio-Economic Systems and Social Work (pp. 207-223). Springer, Cham.

[23] Albelbisi, N., Yusop, F. D., \& Salleh, U. K. M. (2018). Mapping the factors influencing success of massive open online courses (MOOC) in Higher Education. Eurasia Journal of Mathematics, Science and Technology Education, 14(7), 2995-3012.

[24] Li, W., Zhu, Y., \& Ma, X. (2019, August). Influences and Enlightenment of MOOC in Higher Education. In 2019 5th International Conference on Social Science and Higher Education (ICSSHE 2019). Atlantis Press.

[25] Cheng-lin, H., \& Jian-wei, C. (2016). SWOT Analysis on the Development of MOOC in China's Higher Education. American Journal of Educational Research, 4(6), 488-490.

[26] Czerniewicz, L., Deacon, A., Glover, M., \& Walji, S. (2017). MOOC-making and open educational practices. Journal of Computing in Higher Education, 29(1), 81-97.

[27] Lu, H. L., Huang, H. Y., \& Ye, Q. Y. (2018, April). The development of MOOC and its impact on higher education in China. In 2018 International Conference on Education Reform and Management Science (ERMS 2018). Atlantis Press.

[28] Larionova, V., Brown, K., Bystrova, T., \& Sinitsyn, E. (2018). Russian perspectives of online learning technologies in higher education: An empirical study of a MOOC. Research in comparative and international education, 13(1), 70-91.

[29] Tang, S. (2017). Learning Mechanism and Function characteristics of MOOC in the process of higher education. Eurasia Journal of Mathematics, Science and Technology Education, 13(12), 8067-8072.

[30] Huang, L., Zhang, J., \& Liu, Y. (2017). Antecedents of student MOOC revisit intention: Moderation effect of course difficulty. International Journal of Information Management, 37(2), 84-91. 